\title{
Population genetic structure and implications for natal philopatry of nesting green turtles Chelonia mydas in the Yaeyama Islands, Japan
}

\author{
Hideaki Nishizawa ${ }^{1, *}$, Osamu Abe ${ }^{2}$, Junichi Okuyama ${ }^{1}$, Masato Kobayashi ${ }^{2}$, \\ Nobuaki Arai ${ }^{1}$ \\ ${ }^{1}$ Graduate School of Informatics, Kyoto University, Yoshida Honmachi, Sakyo-ku, Kyoto, 606-8501, Japan \\ ${ }^{2}$ Ishigaki Tropical Station, Seikai National Fisheries Research Institute, Fisheries Research Agency, Fukaiohta 148-446, \\ Ishigaki, Okinawa 907-0451, Japan
}

\begin{abstract}
Patterns of mitochondrial DNA (mtDNA) variation and microsatellite genotyping were used to analyze the population genetic structure of nesting green turtles Chelonia mydas $(\mathrm{n}=67)$ in the Yaeyama Islands of Japan, which represent the northern limit of green turtle nesting in the western Pacific Ocean. The composition of a mixture of 6 mtDNA haplotypes from 3 rookeries, southwestern (SW) Iriomote Island $(n=26)$, eastern (E) Ishigaki Island $(n=29)$, and northwestern (NW) Ishigaki Island $(n=12)$, produced genetic diversity values (haplotype diversity $h=0.582$ to 0.638 , nucleotide diversity $\pi=0.0138$ to 0.0244 ) within the high end of the range found in previous studies. The phylogeny of haplotypes, representing 3 distinct clades, indicated historical introgressions by individuals with divergent haplotypes from both Pacific colonies and Indian and Southeast Asian colonies. Significant genetic differentiation, at least between SW Iriomote Island and Ishigaki Island in which samples from E and NW Ishigaki were combined, was observed based on mtDNA; this indicated precise female natal philopatry compared to other Pacific and Indian regions, although microsatellite analyses of 4 markers revealed no significant genetic differentiation. Further studies are needed to clarify the precision of natal philopatry and male-mediated gene flow; however, this study provides valuable insights about the phylogeography of green turtles in Japan. Our results also underscore the need for green turtle conservation in the northwest Pacific Ocean.
\end{abstract}

KEY WORDS: Sea Turtle $\cdot$ Pacific Ocean $\cdot$ mtDNA $\cdot$ Phylogeography $\cdot$ Conservation $\cdot$ Microsatellite Chelonia mydas

Resale or republication not permitted without written consent of the publisher

\section{INTRODUCTION}

The green turtle Chelonia mydas is a long-lived, primarily herbivorous sea turtle species that is globally distributed in tropical and subtropical waters. It is listed as Endangered on the IUCN Red List of Threatened Species (IUCN 2010). In Japan, the Yaeyama and Ogasawara Islands are major nesting grounds for green turtles (Abe et al. 2003), while the wide range of coastal waters along the Japanese archipelago are their feeding grounds (Hamabata et al. 2009). Mitigation of the incidental capture of green turtles by fish- eries (Gilman et al. 2010) and the establishment of coastal management for conserving their nesting habitat (Watanabe 2010) have been partially achieved in Japan, but information on population structure is required for effective conservation.

Genetic analyses are commonly used to investigate the geographic differentiation, population structure, and migration (Bowen \& Karl 2007 and references therein) of this endangered species. Although patterns of mitochondrial DNA (mtDNA) variation of green turtles in Japanese feeding grounds have been published recently (Hamabata et al. 2009, Nishizawa et al. 2010), 
genetic variation in the green turtles nesting in Japan remains poorly understood. This paucity of genetic information on populations in the northwestern Pacific has hindered prioritization of green turtle conservation in the northwest Pacific. In this report, we present mtDNA sequences from nesting green turtles in the Yaeyama islands, Japan, where relatively small but consistent numbers of turtles nest (estimated number of total nesting females on Ishigaki Island in the Yaeyama Islands is 75 at most; Abe et al. 2003). Despite this relatively small annual nesting population size, the present study is important for revealing genetic diversity, phylogeography, and the migration of green turtles in the northwestern Pacific region.

First, we discuss the phylogeographic relationship implied by patterns of mtDNA haplotypes. A matrilineal genealogy from the mtDNA of Atlantic green turtle nesting populations has suggested phylogeographic patterns that could be interpreted as historical dispersal events from equatorial regions to higher latitudes after the Last Glacial Maximum (Encalada et al. 1996, Reece et al. 2005). In the Western Pacific and Indian Oceans, however, the phylogeographic relationships of green turtles between equatorial regions and higher latitudes remain to be validated. The Yaeyama Islands are of particular biogeographic interest for green turtle studies because they are the northern limit of their nesting in the Pacific Ocean. Therefore, the Yaeyama nesting populations are thought to exhibit a genetic structure reflecting colonization from equatorial re- gions, as in the Atlantic (Encalada et al. 1996, Reece et al. 2005).

Second, we examined the genetic differentiation among Yaeyama nesting rookeries, located within $60 \mathrm{~km}$ of one another, to estimate management units and the precision of natal homing (Dethmers et al. 2006). Female turtles are known to nest at their natal areas at ecological timescales (Encalada et al. 1996, Bowen \& Karl 2007), resulting in significant genetic differentiation among rookeries (Norman et al. 1994, Bass et al. 1996). However, the geographical specificity of homing is uncertain, and thus the issues of genetic differentiation among rookeries and precision in natal homing require additional research. We employed microsatellite typing in addition to mtDNA control region sequencing because of their complementary features.

\section{MATERIALS AND METHODS}

Samples. In total, we sampled 67 nesting females from nesting sites on Ishigaki and Iriomote Islands in the Yaeyama group of islands, Japan (Fig. 1). Nesting females were identified by tagging during nightly patrols. Small pieces of tissue (ca. $5 \mathrm{~mm}$ in diameter), which were recovered while punching hind flippers for tagging, were collected and stored in $99 \% \mathrm{EtOH}$. Nesting sites were divided geographically into southwestern (SW) Iriomote Island $(n=26)$, eastern $(E)$ Ishi-

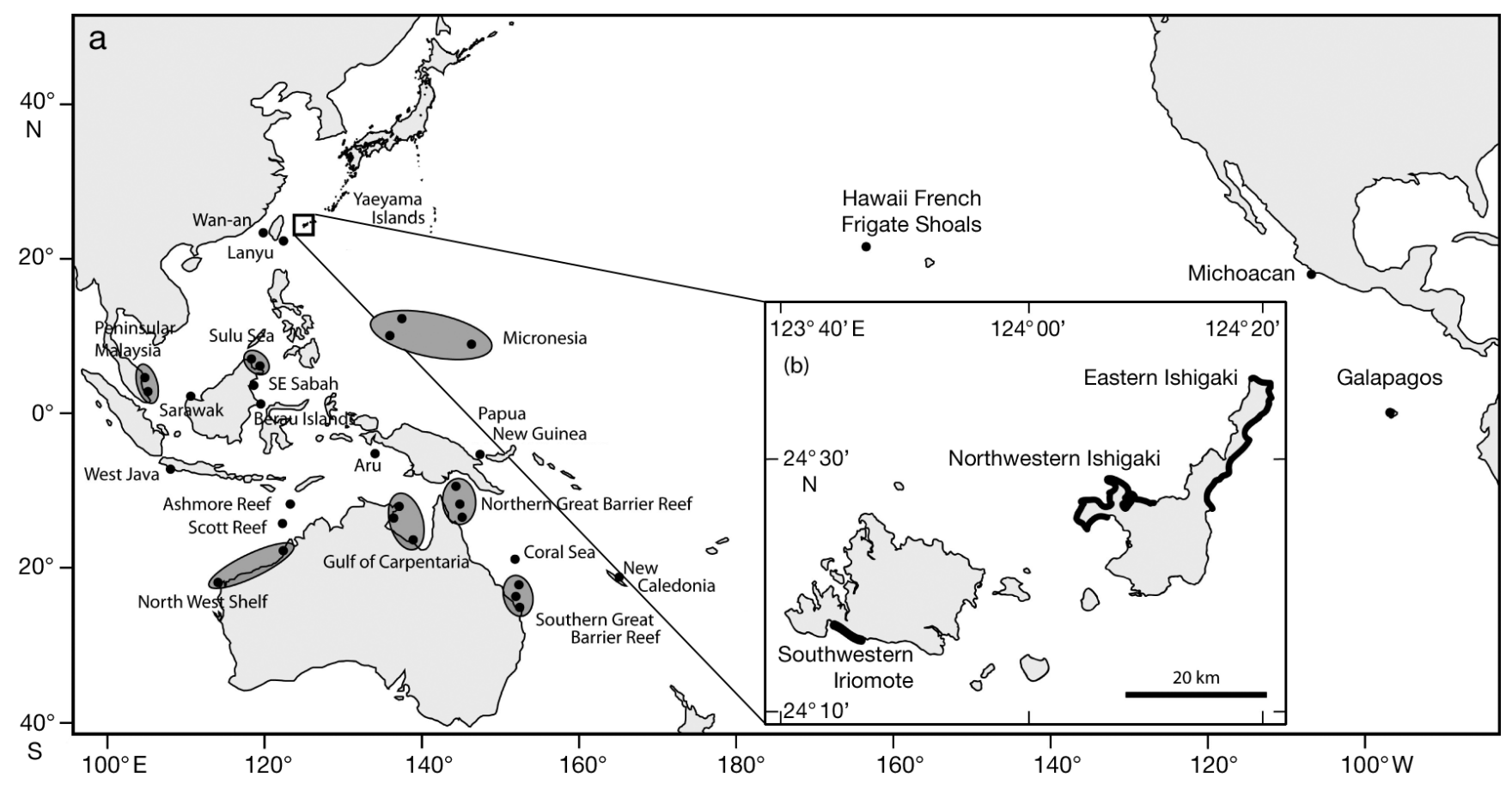

Fig. 1. Geographical locations of (a) the Yaeyama Islands ( $\square$ ) and other Pacific nesting rookeries ( $\bullet$ ) and (b) green turtle nesting sites sampled within the Yaeyama Islands (thick black lines) 
gaki Island ( $\mathrm{n}=29$ ), and northwestern (NW) Ishigaki Island ( $\mathrm{n}=12 ;$ Fig. 1). Samples were collected in 1998 ( $\mathrm{n}=1), 2003$ ( $\mathrm{n}=1), 2006(\mathrm{n}=10), 2007$ ( $\mathrm{n}=29)$, and 2008 ( $n=26)$.

Analysis of mtDNA sequences. DNA was extracted from a small amount of tissue and prepared for polymerase chain reaction (PCR) using the Blood \& Tissue Genomic DNA Extraction Miniprep System (Viogene). An approximately 520 bp segment of the mtDNA control region was amplified with PCR using the primers CMMTF1 (5'-CTT AAA CCT TCA TCC CCG GTC-3') and TCR6 (5'-CAA GTA AAA CTA CCG TAT GCC AGG-3'; Norman et al. 1994) and semi-nested PCR using the primers LTCM2 (5'-GGT CCC CAA AAC CGG AAT CC-3'; Encalada et al. 1996) and TCR6, as described by Nishizawa et al. (2010). Typically, $3 \mu \mathrm{l}$ of template were used in a $20 \mu \mathrm{l}$ PCR reaction containing $2.0 \mu \mathrm{l} 10 \times$ PCR buffer, $1.6 \mu \mathrm{l}$ dNTPs (at $2 \mathrm{mM}$ ), $1.0 \mu \mathrm{l}$ forward and reverse primers (at $2.0 \mu \mathrm{M}$ ), and $0.1 \mu$ ExTaq polymerase (Takara) using standardized conditions of denaturing at $94^{\circ} \mathrm{C}$ for $30 \mathrm{~s}$, annealing at $56^{\circ} \mathrm{C}$ for $30 \mathrm{~s}$, and extension at $72^{\circ} \mathrm{C}$ for $60 \mathrm{~s}$ (35 cycles). The sequencing reactions (forward and reverse) were performed using the BigDye Terminator v3.1 Cycle Sequencing Kit (Applied Biosystems; see Nishizawa et al. 2010 for details). Products were purified with the CleanSEQ (Agencourt; Beckman Coulter) and analyzed using a 3130xl Sequencing Analyzer (Applied Biosystems).

Sequence alignments were performed using CLUSTALW v2.0 (Larkin et al. 2007). Population genetic parameters, nucleotide diversity $(\pi)$ and haplotype diversity $(h)$, were estimated in ARLEQUIN v3.1 (Excoffier et al. 2005). A neighbor-joining tree (Saitou \& Nei 1987) was constructed, and bootstrap analysis (10000 replicates) was performed using MEGA v4.0 (Tamura et al. 2007). For all tests that required estimates of sequence divergence, we used the TamuraNei model of nucleotide substitutions, which was designed for control region sequences (Tamura \& Nei 1993). Although FindModel (www.hiv.lanl.gov/) showed that the best-fit model of nucleotide substitution was the Hasegawa-Kishino-Yano model (Akaike's information criterion $[\mathrm{AIC}]=1703.89$; Hasegawa et al. 1985) and that the second best-fit model was the Tamura-Nei model (AIC $=1705.84$ ), we adopted the more general Tamura-Nei model because it is supported in most population genetic analyses software packages, as noted by Dethmers et al. (2006).

Population differentiation among Yaeyama rookeries was evaluated using an analysis of molecular variance (AMOVA; 10000 permutations; Excoffier et al. 1992), pairwise genetic differentiation $\left(\Phi_{\mathrm{ST}}\right)$ tests (10 000 permutations), and an exact test of population differentiation (500 000 steps in a Markov chain with a
10000 -step dememorization; Raymond \& Rousset 1995) in ARLEQUIN. These tests were also conducted for comparisons between Yaeyama and other Pacific nesting populations (Fig. 1): Taiwanese rookeries (Cheng et al. 2008), eastern Pacific rookeries of Mexico (Chassin-Noria et al. 2004), Hawaii, and Galapagos (Dutton et al. 2008), and 17 Australasian rookeries defined by Dethmers et al. (2006). Sequences were truncated to $380 \mathrm{bp}$ for these comparisons.

Analysis of microsatellite loci. We used 4 microsatellite markers (Cc1G02, Cc8E07, Cc5H07, Cc7E11) developed recently for loggerhead turtles (Shamblin et al. 2007) but that are polymorphic in green turtles (primers for Cc8E07 were modified). Primers were labeled at the 5' end with FAM, VIC, or NED fluorescent dyes. Typically, a $3 \mu$ template was used in $20 \mu \mathrm{l}$ PCR reactions containing $2.0 \mu \mathrm{l} 10 \times$ PCR buffer, $2.0 \mu \mathrm{l}$ dNTPs (at $2 \mathrm{mM}$ ), $0.8 \mu \mathrm{MgSO}_{4}$ (at $25 \mathrm{mM}$ ), $1.5 \mu \mathrm{l}$ forward and reverse primers (at $2.0 \mu \mathrm{M}$ ), and $0.4 \mu \mathrm{KOD}-$ Plus (Toyobo) under the following conditions: $2 \mathrm{~min}$ at $94^{\circ} \mathrm{C}$, followed by 35 cycles of $15 \mathrm{~s}$ at $94^{\circ} \mathrm{C}, 30 \mathrm{~s}$ at $58^{\circ} \mathrm{C}$, and $20 \mathrm{~s}$ at $68^{\circ} \mathrm{C}$. Genotypes were determined by approximate allele size using a 3130 Sequencing Analyzer and GENEMAPPER v3.5 software with GeneScan 500 LIZ (all from Applied Biosystems) as the size standard. We tested conformity to Hardy-Weinberg expectations and independent assortment using ARLEQUIN v3.1. Expected heterozygosity was calculated at each locus for each population using ARLEQUIN, and population heterozygosities were compared while controlling for between-locus variation using an unreplicated 2-way analysis of variance (ANOVA).

The genetic heterogeneity of all populations and between pairwise populations was determined using an exact test (G-based test) that assumes random samples of alleles implemented in GENEPOP v4.0 (Rousset 2008). The null hypothesis was that alleles were drawn from the same distribution in all populations. Fixation indices based on an infinite allele model, $F_{\mathrm{ST}}$ (Weir \& Cockerham 1984), and a stepwise mutation model, $R_{\mathrm{ST}}$ (Slatkin 1995), were estimated using ARLEQUIN to determine the extent of population subdivision among samples.

\section{RESULTS}

Screening for polymorphisms within the $520 \mathrm{bp}$ mtDNA control region fragment among 67 turtles revealed 6 distinct haplotypes (Table 1). Of 32 polymorphic sites, 28 were transitions, 1 contained both a transition and transversion, and 3 were characterized by indels. A $3 \mathrm{bp}$ deletion was unique to haplotype CMJ25 (GenBank accession no. AB472324), and a 
Table 1. Frequencies of mitochondrial DNA (mtDNA) haplotypes (GenBank accession nos. AB472305, AB472307, AB472310, AB472315, AB472317, AB472324), haplotype diversities $(h)$, and nucleotide diversities $(\pi)$ among rookeries in the Yaeyama Islands: southwestern (SW) Iriomote Island, eastern (E) Ishigaki Island, and northwestern (NW) Ishigaki Island. Haplotype nomenclature follows Hamabata et al. (2009) and Nishizawa et al. (2010), but the CMP system is also used (http://swfsc. noaa.gov/). The nomenclature of the clades corresponds to Dethmers et al. (2006)

\begin{tabular}{|c|c|c|c|c|c|c|c|c|c|}
\hline \multirow{2}{*}{ Rookery } & \multirow{2}{*}{$\begin{array}{l}\text { CMJ6/ } \\
\text { CMP54 }\end{array}$} & \multirow{2}{*}{$\begin{array}{l}\text { Clade V } \\
\text { CMJ8/ } \\
\text { CMP20 }\end{array}$} & \multirow{2}{*}{$\begin{array}{l}\text { CMJ11/ } \\
\text { CMP77 }\end{array}$} & \multirow{2}{*}{$\begin{array}{l}\text { I } \\
\text { CMJ18/ } \\
\text { CMP39 }\end{array}$} & \multirow{2}{*}{$\overline{\mathrm{CMJ} 16}$} & \multirow{2}{*}{$\begin{array}{c}\text { I } \\
\text { CMJ25/ } \\
\text { CMP50 }\end{array}$} & \multirow{2}{*}{ Total } & \multirow{2}{*}{$\begin{array}{l}\text { Haplotype } \\
\text { diversity } \\
\text { (h) }\end{array}$} & \multirow{2}{*}{$\begin{array}{l}\text { Nucleotide } \\
\text { diversity } \\
(\pi)\end{array}$} \\
\hline & & & & & & & & & \\
\hline SW Iriomote Island & 14 & 1 & & & 1 & 10 & 26 & 0.582 & 0.0244 \\
\hline E Ishigaki Island & 17 & 4 & 2 & 1 & 3 & 2 & 29 & 0.638 & 0.0138 \\
\hline NW Ishigaki Island & 7 & 1 & & 4 & & & 12 & 0.591 & 0.0147 \\
\hline
\end{tabular}

single base insertion distinguished haplotypes CMJ16 (AB472315) and CMJ18 (AB472317) from the others. A duplication of $4 \mathrm{bp}$ was found in haplotypes CMJ16, CMJ18, and CMJ25. The 6 haplotypes differed by between 1 and 26 observed mutations. The neighborjoining tree of the 6 haplotypes (Fig. 2) identified 3 distinct clades corresponding to 3 of the 5 clades of haplotypes observed in Australasian nesting populations (Dethmers et al. 2006). Haplotypes CMJ8 (AB472307) and CMJ11 (AB472310) in the present study contained sequences identical to A3 (CMP20) and A4 (CMP77), respectively, presented by Dethmers et al. (2006). In addition, when haplotypes detected from the Yaeyama Islands were compared to those found in the Pacific and listed on the Southwest Fisheries Science Center website (http://swfsc.noaa.gov/textblock.aspx?Division =PRD\&ParentMenuId=212\&id=11212), CMJ6, CMJ18, and CMJ25 contained sequences identical to CMP54, CMP39, and CMP50, respectively. CMJ16 did not match any sequences listed in this website.

Despite the identification of divergent clades, phylogeographic structuring among rookeries was diminished by the occurrence of several common haplotypes (Table 1). That is, CMJ6 was observed in all populations at relatively high frequencies. In addition, all

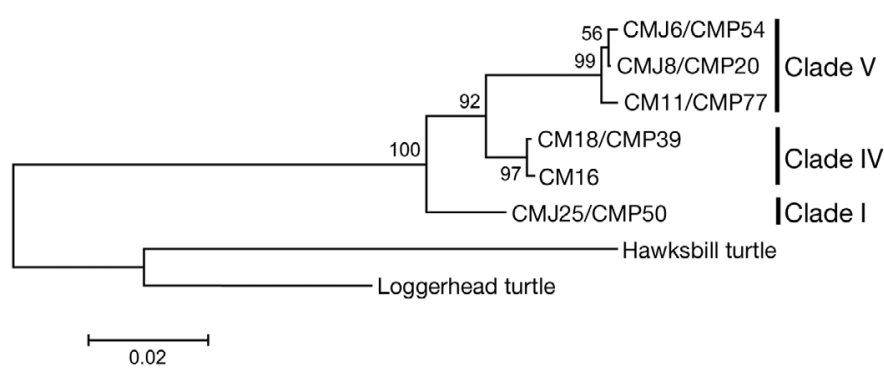

Fig. 2. Green turtle phylogeny describing the relationships among 6 mitochondrial DNA (mtDNA) control region haplotypes (the CMP system is also used; http://swfsc.noaa.gov/). Nomenclatures of the clades correspond to Dethmers et al. (2006). Neighbor-joining tree shows percent bootstrap support. Branch lengths are proportional to the percent sequence divergence indicated by the scale populations exhibited haplotypes in multiple clades. This was reflected in the AMOVA results, which indicated that $88.11 \%$ of the genetic variability resided within rookeries. The variance component among populations was small (11.89\%) relative to that within populations but was nonetheless significant $\left(\Phi_{\mathrm{ST}}=0.1189\right.$, $\mathrm{p}=0.011$ ). Pairwise $\Phi_{\mathrm{ST}}$ tests (Table 2a) indicated a significant differentiation between $E$ Ishigaki Island and SW Iriomote Island $\left(\Phi_{\mathrm{ST}}=0.1389, \mathrm{p}=0.012\right)$. The NW Ishigaki Island population was also significantly differentiated from that of SW Iriomote Island $\left(\Phi_{\mathrm{ST}}=0.1495\right.$, $\mathrm{p}=0.030)$, but the significance disappeared after sequential Bonferroni correction. Exact tests based on haplotype frequencies (Table 2a) confirmed the population differentiations between SW Iriomote and E Ishigaki ( $p=0.024)$ or NW Ishigaki $(p=0.002)$ islands, but no significant differentiation between the E and NW Ishigaki rookeries $(p=0.150)$.

We combined the E and NW Ishigaki rookeries, which individually showed no significant differentiation, and repeated the tests for population subdivision such that they examined relationships between SW Iriomote and Ishigaki Islands. The comparison indicated a highly significant population differentiation (Table 2b) between these rookeries (AMOVA p $=0.003 ; \Phi_{\mathrm{ST}}=$ $0.1578, p=0.002$; exact test $p=0.004)$. When we reanalyzed with samples from 2006 to 2008 for clarification, taking out the samples from years when only 1 sample was collected, population differentiation between SW Iriomote and Ishigaki Islands was still strongly supported (AMOVA $\mathrm{p}=0.004 ; \Phi_{\mathrm{ST}}=0.1511, \mathrm{p}=0.004$; exact test $\mathrm{p}=0.004)$.

Population differentiations between SW Iriomote or Ishigaki and other Pacific nesting populations were confirmed by the exact tests (all pairwise comparisons indicated $\mathrm{p}<0.00001)$. $\Phi_{\mathrm{ST}}$ values for most comparisons were significant $\left(\Phi_{\mathrm{ST}}>0.1532, \mathrm{p}<0.012\right)$, but the $\Phi_{\mathrm{ST}}$ value for SW Iriomote and Ashmore Reef (Dethmers et al. 2006) was not significant $\left(\Phi_{\mathrm{ST}}=0.0006, \mathrm{p}=\right.$ 0.293) and that for Ishigaki and Papua New Guinea was significant but slight $\left(\Phi_{\mathrm{ST}}=0.0734, \mathrm{p}=0.040\right.$; Table 3). 
Table 2. Genetic population differentiations based on either mitochondrial (mtDNA) $(\mathrm{a}, \mathrm{b})$ haplotypes or $(\mathrm{c}, \mathrm{d})$ microsatellite alleles. Statistics among southwestern (SW) Iriomote Island, eastern (E) Ishigaki Island, and northwestern (NW) Ishigaki Island $(\mathrm{a}, \mathrm{c})$ and those between SW Iriomote Island and Ishigaki Island in which E and NW Ishigaki Island were combined $(\mathrm{b}, \mathrm{d})$ are shown. Above the diagonal are p-values of the exact tests for population differentiation, and below the diagonal are partitions based on genetic differentiation values of $\Phi_{\mathrm{ST}}(\mathrm{a}, \mathrm{b})$ or $F_{\mathrm{ST}}(\mathrm{c}, \mathrm{d})$ and $\mathrm{p}$-values of permutation tests. Values in bold indicate significant differentiation after sequential Bonferroni correction

(a) mtDNA-based population differentiation (among 3 rookeries) SW Iriomote Is. E Ishigaki Is. NW Ishigaki Is.

\begin{tabular}{lccc}
\hline SW Iriomote Is. & - & $\mathbf{p}=\mathbf{0 . 0 2 4}$ & $\mathbf{p}=\mathbf{0 . 0 0 2}$ \\
E Ishigaki Is. & $\mathbf{0 . 1 3 8 9}(\mathrm{p}=0.013)$ & - & $\mathrm{p}=0.150$ \\
NW Ishigaki Is. & $0.1495(\mathrm{p}=0.032)$ & $-0.0016(\mathrm{p}=0.306)$ & - \\
\hline
\end{tabular}

(b) mtDNA-based population differentiation (between 2 rookeries) SW Iriomote Is. Ishigaki Is.

\begin{tabular}{lcc}
\hline SW Iriomote Is. & - & $\mathbf{p}=\mathbf{0 . 0 0 4}$ \\
Ishigaki Is. & $\mathbf{0 . 1 5 7 8}(\mathrm{p}=0.002)$ & - \\
\hline
\end{tabular}

(c) Microsatellite-based population differentiation (among 3 rookeries) SW Iriomote Is. E Ishigaki Is. NW Ishigaki Is.

\begin{tabular}{lccc}
\hline SW Iriomote Is. & - & $\mathrm{p}=0.173$ & $\mathrm{p}=0.476$ \\
E Ishigaki Is. & $0.0025(\mathrm{p}=0.308)$ & - & $\mathrm{p}=0.771$ \\
NW Ishigaki Is. & $-0.0029(\mathrm{p}=0.585)$ & $0.0037(\mathrm{p}=0.300)$ & - \\
\hline
\end{tabular}

(d) Microsatellite-based population differentiation (between 2 rookeries) SW Iriomote Is. Ishigaki Is.

SW Iriomote Is. $\quad-\quad p=0.104$ Ishigaki Is. $-0.0001(\bar{p}=0.434)$

$-$
Four primer pairs of microsatellite loci generated polymorphic products. For Cc1G02 and Cc7E11, all alleles were distinguished by increments of 4 $\mathrm{bp}$, whereas for Cc8E07 and Cc5H07, alleles exhibited $1 \mathrm{bp}$ increments in addition to $4 \mathrm{bp}$ increments. This may reflect an indel mutation, but we did not take this mutation into consideration in our subsequent analyses because it would have exhibited a different mutation rate than a slippage of $4 \mathrm{bp}$. No deviations from Hardy-Weinberg equilibrium (Table 4) or significant linkage disequilibrium were detected after sequential Bonferroni correction. All 4 microsatellite loci showed high levels of polymorphism, with 11 to 18 alleles and expected heterozygosities ranging from 0.73 to 0.91 (Table 4).

Expected heterozygosity did not vary significantly between populations (2way ANOVA; $\mathrm{p}=0.791$ ), taking into account differences in heterozygosity between loci ( $p=0.005)$. In addition, genetic differentiation tests of all populations and pairwise populations (Table 2c) revealed no significant differentiation among loci (all popula-

Table 3. Genetic differentiation values of $\Phi_{\mathrm{ST}}$ and p-values (in parentheses) for comparisons between Yaeyama rookeries and other Pacific rookeries

\begin{tabular}{|llll}
\hline & SW Iriomote Island & Ishigaki Island & Source \\
\hline Wan-an (Taiwan) & $0.1681(0.006)$ & $0.4381(<0.00001)$ & Cheng et al. (2008) \\
Lanyu (Taiwan) & $0.4901(<0.001)$ & $0.7529(<0.00001)$ & Cheng et al. (2008) \\
Northern Great Barrier Reef (Australia) & $0.5725(<0.00001)$ & $0.6763(<0.00001)$ & Dethmers et al. (2006) \\
Coral Sea (Australia) & $0.2392(<0.00001)$ & $0.2339(<0.00001)$ & Dethmers et al. (2006) \\
Southern Great Barrier Reef (Australia) & $0.5158(<0.00001)$ & $0.4154(<0.00001)$ & Dethmers et al. (2006) \\
New Caledonia & $0.2730(0.005)$ & $0.4660(<0.00001)$ & Dethmers et al. (2006) \\
Micronesia & $0.4719(<0.00001)$ & $0.2579(<0.00001)$ & Dethmers et al. (2006) \\
Papua New Guinea & $0.2113(0.012)$ & $0.0734(0.040)$ & Dethmers et al. (2006) \\
Gulf of Carpentaria (Australia) & $0.7198(<0.00001)$ & $0.8580(<0.00001)$ & Dethmers et al. (2006) \\
Aru (Indonesia) & $0.5037(<0.00001)$ & $0.7494(<0.00001)$ & Dethmers et al. (2006) \\
Berau Island (Indonesia) & $0.4826(<0.00001)$ & $0.7355(<0.00001)$ & Dethmers et al. (2006) \\
SE Sabah (Malaysia) & $0.5674(<0.00001)$ & $0.7881(<0.00001)$ & Dethmers et al. (2006) \\
Sulu Sea (Malaysia and Philippines) & $0.7073(<0.00001)$ & $0.8557(<0.00001)$ & Dethmers et al. (2006) \\
Sarawak (Malaysia) & $0.4686(<0.00001)$ & $0.7198(<0.00001)$ & Dethmers et al. (2006) \\
Peninsular Malaysia (Malaysia) & $0.4478(<0.00001)$ & $0.7080(<0.00001)$ & Dethmers et al. (2006) \\
Ashmore Reef (Australia) & $0.0064(0.293)$ & $0.2489(<0.001)$ & Dethmers et al. (2006) \\
Scott Reef (Australia) & $0.4457(<0.00001)$ & $0.7170(<0.00001)$ & Dethmers et al. (2006) \\
West Java (Indonesia) & $0.5324(<0.00001)$ & $0.7718(<0.00001)$ & Dethmers et al. (2006) \\
Northwest Shelf (Australia) & $0.5874(<0.00001)$ & $0.7866(<0.00001)$ & Dethmers et al. (2006) \\
Michoacan (Mexico) & $0.7539(<0.00001)$ & $0.8615(<0.00001)$ & Chassin-Noria et al. (2004) \\
Galapagos & $0.7928(<0.00001)$ & $0.8891(<0.00001)$ & Dutton et al. (2008) \\
Hawaii French Frigate Shoals & $0.8232(<0.00001)$ & $0.8997(<0.00001)$ & Dutton et al. (2008) \\
\hline
\end{tabular}


Table 4. Summary statistics for the 4 microsatellite loci used to survey green turtle nesting populations. n: number of tested samples; $A$ : number of alleles; $H_{0}$ : observed heterozygosity; $H_{\mathrm{E}}$ : expected heterozygosity; $P_{\mathrm{HW}}$ : probability that genotype proportions conform to Hardy-Weinberg equilibrium

\begin{tabular}{lcccccc|}
\hline Locus & $\mathrm{n}$ & $A$ & Size (bp) & $H_{0}$ & $H_{\mathrm{E}}$ & $P_{\mathrm{HW}}$ \\
\hline Cc8E07 & 67 & 18 & $260-340$ & 0.925 & 0.913 & 0.959 \\
Cc1G02 & 67 & 14 & $234-290$ & 0.672 & 0.806 & 0.136 \\
Cc7E11 & 67 & 11 & $256-312$ & 0.791 & 0.729 & 0.411 \\
Cc5H07 & 67 & 15 & $212-272$ & 0.925 & 0.908 & 0.205 \\
\hline
\end{tabular}

tions: $p>0.165$; pairwise populations: $p>0.102$ ) and over all loci (all populations: $p=0.336$, pairwise populations: $p>0.173$ ), indicating no population subdivision. Contrary to the mtDNA surveys, all pairwise comparisons of both $F_{\mathrm{ST}}\left(F_{\mathrm{ST}}<0.0037, \mathrm{p}>0.300\right)$ and $R_{\mathrm{ST}}$ values $\left(R_{\mathrm{ST}}<0.0555, \mathrm{p}>0.029\right)$ indicated no significant population differentiation after sequential Bonferroni correction. When E and NW Ishigaki rookeries were combined and reanalyzed, these tests revealed no significant difference (Table 2d) between SW Iriomote and Ishigaki Islands (exact test $\mathrm{p}=0.106 ; F_{\mathrm{ST}}=0.0001$, $\left.\mathrm{p}=0.463 ; R_{\mathrm{ST}}=0.0035, \mathrm{p}=0.255\right)$.

\section{DISCUSSION}

Here we have reported the sequences of nesting green turtles in the northwestern Pacific for the first time. The patterns of mtDNA indicated some characteristic features. The 3 clades observed in this study (Fig. 2) correspond to 3 of the 5 clades of haplotypes observed in Australasian nesting populations (Dethmers et al. 2006). Composition of a mixture of divergent haplotypes of mtDNA in all rookeries in our study resulted in genetic diversity values within the high end of the range found for other sea turtle populations (Lahanas et al. 1994, Encalada et al. 1996, Chassin-Noria et al. 2004, Dethmers et al. 2006, Bourjea et al. 2007; Table 1). The high $\pi$ values may reflect historical introgressions by individuals with divergent haplotypes or multiple colonization events (Chassin-Noria et al. 2004, Cheng et al. 2008). Actually, comparisons between Yaeyama and other Pacific rookeries indicated that nesting populations of SW Iriomote or Ishigaki have more similar genetic structure to those of Ashmore Reef in Australia, or Papua New Guinea (Dethmers et al. 2006), respectively, than nearer Taiwanese populations (Cheng et al. 2008; Table 3). This probably reflects that nesting populations of Ashmore Reef and Papua New Guinea have haplotypes from Clades I and $\mathrm{V}$ and contain CMJ8/CMP20.
During the Last Glacial Maximum, the advancement of continental ice sheets and the consequent drop in sea level probably reduced the range of suitable sea turtle habitats to a narrow tropical margin (Encalada et al. 1996, 1998). Thus, equatorial regions have served as green turtle refugia during glacial maxima, with subsequent colonizations to higher latitudes during warmer interglacial periods (Encalada et al. 1996, Reece et al. 2005). In the southwestern Pacific, a land barrier formed between northeastern Australia and New Guinea during the Pleistocene was thought to induce genetic breaks of Australasian green turtles between the Pacific and Indian oceans and Southeast Asian populations (Dethmers et al. 2006). Clade V was dominant in the Pacific rookeries, and Clades IV and I were dominant in the Indian Ocean and Southeast Asian rookeries, respectively (Dethmers et al. 2006). Because the nesting populations on the Yaeyama Islands, located in the western Pacific at the northern limit of the green turtle nesting range, exhibit both of these distinct haplotypes, the populations would have colonized both from equatorial Australasian and Southeast Asian regions after glacial periods.

The results of mtDNA analyses in this study showed a significant population subdivision at least between SW Iriomote Island and Ishigaki Island (Table 2b). In previous studies, analyses of mtDNA structure found that geographically distant rookeries exhibited heterogeneous haplotype frequencies, supporting female natal homing (Norman et al. 1994, Encalada et al. 1996). Therefore, although most previous mtDNA studies on green turtles indicated a lack of population differentiation among rookeries within $150 \mathrm{~km}$ (Chassin-Noria et al. 2004, Dethmers et al. 2006, Bourjea et al. 2007), the nesting populations on the Yaeyama Islands appear to be differentiated between rookeries within $60 \mathrm{~km}$. Genetic differentiation within similar geographic range is also found in those on Taiwanese rookeries (Cheng et al. 2008). The $\Phi_{\mathrm{ST}}$ value indicated that the NW Ishigaki Island population was not significantly differentiated from that of SW Iriomote Island after sequential Bonferroni correction, but the p-value was close to significance. The conservative nature of Bonferroni correction (Moran 2003, Narum 2006) suggests that more samples may confirm the significant difference between NW Ishigaki Island and SW Iriomote Island populations. Alternatively, other methods such as mark-recapture or satellite telemetry are needed to clarify this finding, but precise female natal philopatry was indicated in this study.

We did not detect genetic differentiation from microsatellites (Table 2c,d). As previous studies have noted (FitzSimmons et al. 1997, Roberts et al. 2004, Bowen et al. 2005), male-mediated gene flow between populations can readily explain the reduced popula- 
tion structure registered in nuclear markers relative to mitochondrial markers (Bowen et al. 2005). However, small numbers of samples and markers make this difficult to conclude. Further studies with more samples or markers would be needed.

Recently, regional management units have been suggested to provide a framework for assessing highdiversity areas and evaluating the conservation status of sea turtles (Wallace et al. 2010). Our study revealed that the Yaeyama nesting populations exhibit relatively high genetic diversity, likely as a result of historical emigration from divergent tropical colonies, despite relatively small or obscure numbers of nesting turtles at least in Ishigaki Island (Abe et al. 2003). In Japan, green turtles not only in feeding grounds (Hamabata et al. 2009, Nishizawa et al. 2010) but also on nesting beaches have relatively high genetic diversity. Considering that green turtle nesting populations of Wan-an Island in Taiwan, another nesting rookery in the Northwestern Pacific, also show high genetic diversity (Cheng et al. 2008) and are significantly differentiated from those of the Yaeyama Islands, a regional management unit of Northwestern Pacific green turtles (Wallace et al. 2010) is important in terms of conserving genetic diversity. Moreover, the significant genetic differentiation among the Yaeyama Islands as revealed by mtDNA analysis may indicate precise female natal philopatry, as among Taiwanese rookeries. The findings indicate that nesting females of green turtles in the Yaeyama Islands have precise natal philopatry at ecological timescales, although the nesting populations had been formed by immigration from divergent tropical colonies at historical timescales. Considering that natal philopatry is related to their response to changes in the availability of nesting sites over time (Dethmers et al. 2006), Yaeyama nesting populations may have a high priority for conservation. Although further studies are needed to clarify the precision of natal philopatry and male-mediated gene flow, this study indicated some phylogeographic features of and conservation priorities for northwest Pacific green turtles.

Acknowledgements. We thank S. Tanizaki, H. Ishii, and the other members of the Ishigaki Island Sea Turtle Research Group for providing the samples from Ishigaki Island. Sampling on Iriomote Island was supported by T. Yasuda and T. Yokota (Graduate School of Informatics, Kyoto University). We also thank K. Okuzawa and staff at the Ishigaki Tropical Station and Yaeyama Station, Seikai National Fisheries Research Institute, and D. Imakita (Faculty of Agriculture, Kinki University), K. Ichikawa, Y. Kawabata, and H. Watanabe (Graduate School of Informatics, Kyoto University) for their help with fieldwork and constructive comments. M. Kinoshita and H. Sawada (Graduate School of Agriculture, Kyoto University) kindly supported the extraction and amplification of DNA. R. Matsuoka and T. Nishizawa (IREIIMS,
Tokyo Women's Medical University) kindly helped with the sequencing analysis. We are also much indebted to 2 anonymous reviewers for their constructive comments. The Ministry of the Environment, Japan (no. 080616001), permitted sampling in the Iriomote Ishigaki National Park. This study was partly supported by Informatics Education and Research Center for Knowledge - Circulating Society (Global COE Program).

\section{LITERATURE CITED}

Abe O, Shibuno T, Takada Y, Hashimoto K and others (2003) Nesting populations of sea turtle in Ishigaki Island, Okinawa. Proc 4th SEASTAR2000 Workshop, 11-13 December 2003, Bangkok, p 40-43

Bass AL, Good DA, Bjorndal KA, Richardson JI, Hillis ZM, Horrocks JA, Bowen BW (1996) Testing models of female reproductive migratory behaviour and population structure in the Caribbean hawksbill turtle, Eretmochelys imbricata, with mtDNA sequences. Mol Ecol 5: 321-328

Bourjea J, Lapègue S, Gagnevin L, Broderick D and others (2007) Phylogeography of the green turtle, Chelonia mydas, in the Southwest Indian Ocean. Mol Ecol 16: 175-186

Bowen BW, Karl SA (2007) Population genetics and phylogeography of sea turtles. Mol Ecol 16:4886-4907

Bowen BW, Bass AL, Soares L, Toonen RJ (2005) Conservation implications of complex population structure: lessons from the loggerhead turtle (Caretta caretta). Mol Ecol 14: 2389-2402

Chassin-Noria O, Abreu-Grobois A, Dutton PH, Oyama K (2004) Conservation genetics of the east Pacific green turtle (Chelonia mydas) in Michacan, Mexico. Genetica 121: 195-206

Cheng IJ, Dutton PH, Chen CL, Chen HC, Chen YH, Shea JW (2008) Comparisons of the genetics and nesting ecology of two green turtle rookeries. J Zool 276:375-384

Dethmers KEM, Broderick D, Moritz C, FitzSimmons NN and others (2006) The genetic structure of Australasian green turtles (Chelonia mydas): exploring the geographical scale of genetic exchange. Mol Ecol 15:3931-3946

Dutton PH, Balazs GH, LeRoux RA, Murakawa SKK, Zarate P, Martinez LS (2008) Composition of Hawaiian green turtle foraging aggregations: mtDNA evidence for a distinct regional population. Endang Species Res 5:37-44

- Encalada SE, Lahanas PN, Bjorndal KA, Bolten AB, Miyamoto MM, Bowen BW (1996) Phylogeography and population structure of the Atlantic and Mediterranean green turtle Chelonia mydas: a mitochondrial DNA control region sequence assessment. Mol Ecol 5:473-483

Encalada SE, Bjorndal KA, Bolten AB, Zurita JC and others (1998) Population structure of loggerhead turtle (Caretta caretta) nesting colonies in the Atlantic and Mediterranean as inferred from mitochondrial DNA control region sequences. Mar Biol 130:567-575

Excoffier L, Smouse PE, Quattro JM (1992) Analysis of molecular variance inferred from metric distances among DNA haplotypes: application to human mitochondrial DNA restriction data. Genetics 131:479-491

Excoffier L, Laval G, Schneider S (2005) Arlequin ver. 3.0: an integrated software package for population genetics data analysis. Evol Bioinform Online 1:47-50

FitzSimmons NN, Moritz C, Limpus CJ, Pope L, Prince R (1997) Geographic structure of mitochondrial and nuclear gene polymorphisms in Australian green turtle popula- 
tions and male-mediated gene flow. Genetics 147: 1843-1854

Gilman E, Gearhart J, Price B, Eckert S and others (2010) Mitigating sea turtle by-catch in coastal passive net fisheries. Fish Fish 11:57-88

Hamabata T, Nishida S, Kamezaki N, Koike H (2009) Genetic structure of the green turtle (Chelonia mydas) in Japan using mtDNA control region sequences. Bull Grad Sch Soc Cult Stud Kyushu Univ 15:35-50

Hasegawa M, Kishino H, Yano T (1985) Dating the humanape splitting by a molecular clock of mitochondrial DNA. J Mol Evol 22:160-174

IUCN (2010) IUCN Red List of Threatened Species. Version 2010.4. Available at www.iucnredlist.org (accessed on 14 March 2011)

Lahanas PN, Miyamoto MM, Bjorndal KA, Bolten AB (1994) Molecular evolution and population genetics of Greater Caribbean green turtles (Chelonia mydas) as inferred from mitochondrial DNA control region sequences. Genetica 94:57-67

Larkin MA, Blackshields G, Brown NP, Chenna R and others (2007) Clustal W and Clustal X version 2.0. Bioinformatics 23:2947-2948

Moran MD (2003) Arguments for rejecting the sequential Bonferroni in ecological studies. Oikos 100:403-405

Narum SR (2006) Beyond Bonferroni: less conservative analyses for conservation genetics. Conserv Genet 7: 783-787

> Nishizawa H, Okuyama J, Kobayashi M, Abe O, Arai N (2010) Comparative phylogeny and historical perspectives on population genetics of the Pacific hawksbill (Eretmochelys imbricata) and green turtles (Chelonia mydas), inferred from feeding populations in the Yaeyama Islands, Japan. Zool Sci (Tokyo) 27:14-18

Norman JA, Moritz C, Limpus CJ (1994) Mitochondrial DNA control region polymorphisms: genetic markers for ecological studies of marine turtles. Mol Ecol 3:363-373

Editorial responsibility: Jeffrey Seminoff,

La Jolla, California, USA
Raymond M, Rousset F (1995) An exact test for population differentiation. Evolution 49:1280-1283

Reece JS, Castoe TA, Parkinson CL (2005) Historical perspectives on population genetics and conservation of three marine turtle species. Conserv Genet 6:235-251

Roberts MA, Schwartz TS, Karl SA (2004) Global population genetic structure and male-mediated gene flow in the green sea turtle (Chelonia mydas): analysis of microsatellite loci. Genetics 166:1857-1870

Rousset F (2008) GENEPOP'007: a complete re-implementation of the GENEPOP software for Windows and Linux. Mol Ecol Resour 8:103-106

Saitou N, Nei M (1987) The neighbour-joining method: a new method for reconstructing phylogenetic trees. Mol Biol Evol 4:406-425

Shamblin BM, Faircloth BC, Dodd M, Wood-Jones A, Castleberry SB, Carroll JP, Nairn CJ (2007) Tetranucleotide microsatellites from the loggerhead sea turtle (Caretta caretta). Mol Ecol Notes 7:784-787

- Slatkin M (1995) A measure of population subdivision based on microsatellite allele frequencies. Genetics 139:457-462

Tamura K, Nei M (1993) Estimation of the number of nucleotide substitutions in the control region of mitochondrial DNA in humans and chimpanzees. Mol Biol Evol 10: 512-526

Tamura K, Dudley J, Nei M, Kumar S (2007) MEGA4: Molecular Evolutionary Genetics Analysis (MEGA) software version 4.0. Mol Biol Evol 24:1596-1599

Wallace BP, DiMatteo AD, Hurley BJ, Finkbeiner EM and others (2010) Regional management units for marine turtles: a novel framework for prioritizing conservation and research across multiple scales. PLoS ONE 5:e15465

Watanabe K (2010) A review of attempts to conserve sea turtle nesting habitat through coastal management. Aquabiology 32:455-462 (in Japanese, with English abstract)

> Weir BS, Cockerham CC (1984) Estimating F-statistics for the analysis of population structure. Evolution 38:1358-1370

Submitted: December 29, 2010; Accepted: May 13, 2011

Proofs received from author(s): June 27, 2011 